\title{
Performance and Emission Analysis of Two Stroke Dual Sparkplug SI Engine
}

\author{
T. A. Khan, R. Shaikh \\ (MAulana Mukhtar Ahmad Nadvi Technical Campus, Malegaon, India)
}

\begin{abstract}
An internal combustion (IC) engine has a predominant role in a low power generation and a virtual monopoly in mobile applications today. One of the best methods to improve the engine performance and reduce the exhaust emission in a SI engine is by using introduction of twin spark into the combustion chamber. Two stroke spark ignition engines have high exhaust emissions and low brake thermal efficiency due to the short circuiting losses and incomplete combustion, which occur during idling and at part load operating conditions. Dual spark ignition system has proved their potential in improving the performance of the engines and improved emissive characteristics as compared with the single spark plug ignition system. Experiments were conducted at different load conditions and different types of engines have proved that dual spark plug ignition engines are surely better than a single spark plug engine. To compare, single-spark plug configurations were also considered for other selected spark plug locations. Current paper investigates the effect of multi spark plug to the single spark plug on the basis of the performance of engine and emissive characteristics of engine. The result shown that the considerable improvement in the performance of engine output and considerable reduction in BSFC, HC and Co emission in multi spark plug mode.
\end{abstract}

Keywords - BSFC, CO, Dual Spark Plug, HC, Optimization of Location of Spark Plug, Performance Analysis, SI Engine.

\section{INTRODUCTION}

Most of the internal combustion engines run on the fossil fuel which contain hydrocarbon (HC).Normal combustion products of any IC engine are $\mathrm{CO}_{2}, \mathrm{H}_{2} \mathrm{O}$ and $\mathrm{NO}_{2}$ in the complete combustion process of engine. These exhaust products are not considered as a pollutant because they do not cause direct hazard on human. But normally in real combustion process some additional products such as unburned hydrocarbon (HCs), carbon monoxide, nitrogen oxide (NOx) and particulate matter (PM) also appears. This product creates the most harmful effect on the environment as well as human. Quantity of this harmful product of SI engine is five times more than that of $\mathrm{CI}$ engine. $\mathrm{CO}$ is the dominating pollutant component with about 80 percent of all pollutant emissions, i.e., CO, NOx, unburned HCs and PM. Its high concentration affects the hemoglobin and low concentration is sufficient to cause suffocation. This poisonous gas is mostly generated in to the engine. When engine is operated in fuel rich equivalence ratio and there is not sufficient oxygen to convert all carbon in to $\mathrm{CO}_{2}$, some fuel carbon form into $\mathrm{CO}$. Concentration of nitrogen is about 12 percent. Most of the NOx is in the form of nitrogen monoxide (NO) with small amount of nitrogen dioxide $\left(\mathrm{NO}_{2}\right)$. The rest of the exhaust is in form of HCs and PM. Hydrocarbon are 8\% of total emission and PM concentration is in ppm (part per million) levels. Fossil fuels are them majorly used type of fuel from decades and due to their rapid usage caused the increase in greenhouse gases, degradation of air quality and shortage of fossil fuels. All these have encouraged the development of new technologies with reduces the engine emissions and its fuel efficiency without compromising its power. The main idea behind introducing more than one spark plug per engine cylinder is to complete the combustion process as fast as possible. In SI engines fuels should be ignited exactly at end of compression stroke and before the power stroke, which gives very less time for the flame initiation process.

Studies done by Narsimha Bailkeri et. al [1] has shown that introduction of dual spark ignition has considerably increased the performance of the engine by increasing efficiency \& power and reducing its exhaust emissions. Same results can also be seen in the study done by Ajay K. Singh et. al [2] which proved that dual spark ignition system is better for improving ignition process even in 2-stroke engines. Thus reviews and studies have clearly indicated that use of multiple spark ignitions can increase the rate of combustion by rapidly completing the process. Thus, generating more power increased the engine efficiency and lowers the exhaust emissions.

In this work various performance parameters and emissive characteristics are analyzed in detail for single spark ignition and dual spark ignition engines. Following this section is the instrument and experimental setup used to measure the different engine performances. Next are the result and discussions, followed by conclusion and suggestion made for future work. 


\section{EXPERIMENTAL SETUP AND TEST PROCEDURE}

Experiment conducted on 2-stroke petrol engines with single spark plug and twin spark plug carried out at a constant speed of $3000 \mathrm{rpm}$. The engine specifications are given in table1. Components used to perform the experiment are air cooled single cylinder single spark ignition petrol engine, air cooled single cylinder twin spark ignition petrol engine. Dynamometer, exhaust gas analyzer, fuel consumption device and digital tachometer.

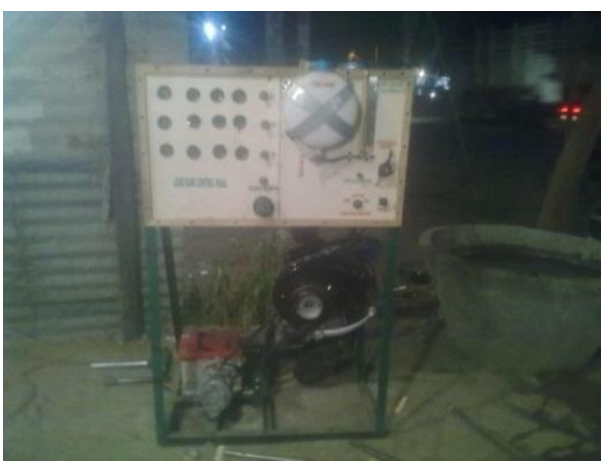

Table.1. Components Required

Fig.1. Experimental setup

The experiment is being carried out at constant speed (say $3000 \mathrm{rpm}$.) Firstly 4 bulbs are lightened and then engine is started for single spark plug. By keeping the throttle constant and hence measuring the speed to be $3000 \mathrm{rpm}$, different apparatus readings are noted i.e. of ammeter, voltmeter, wattmeter, fuel gauge tube, is taken for every $10 \mathrm{sec}$ for each $320 \mathrm{~W}$ load. The process is repeated for every $320 \mathrm{~W}$ load till all the 12 bulbs $(960 \mathrm{~W})$ is lightened.

\section{LOCATION OF SPARK PLUG}

Experimentally investigated that in the single spark plug mode the centrally located spark plug is most effective and gives best performance. In the dual spark plug mode if the central location of the spark plug is not possible because of the design of the engine than spark plugs were considered to be located diametrically opposite to each other on cylinder head axis symmetrically.

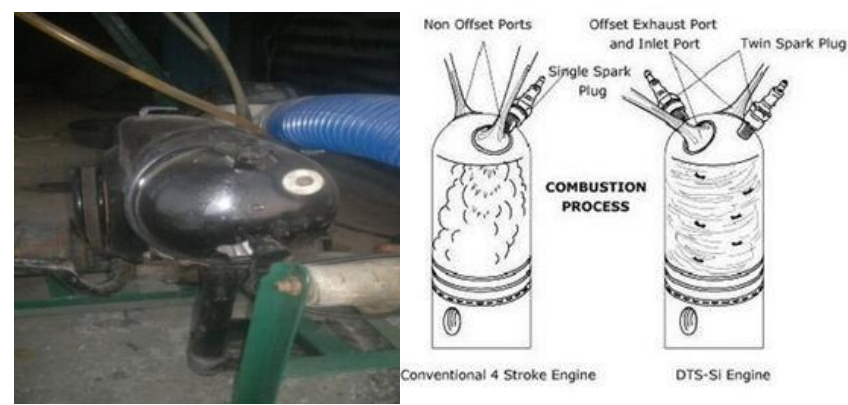

Fig.2. Position of spark plugs

\section{RESULT AND DISCUSSION}

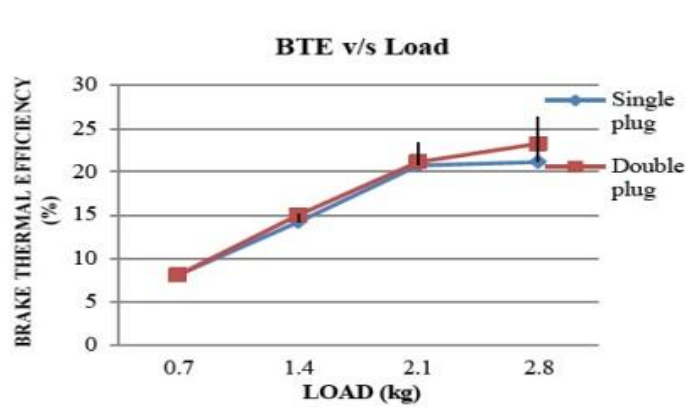

Fig.3. BTE v/s Load

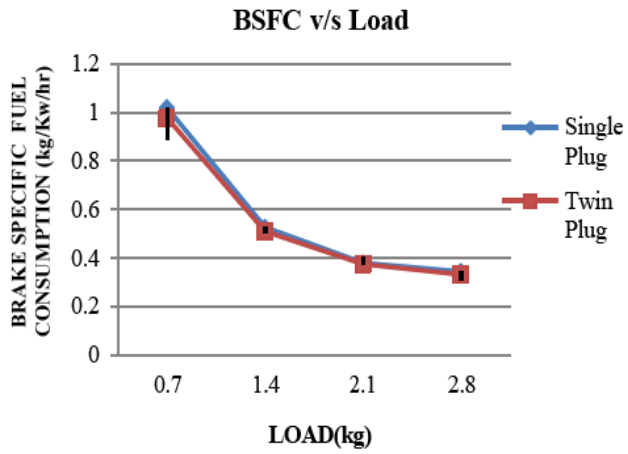

Fig.4. BSFC v/s Load 


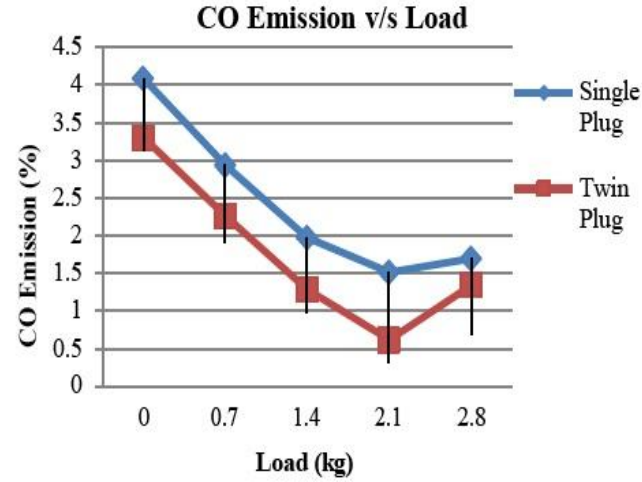

Fig.5. CO emission v/s Load UBHC v/s Load

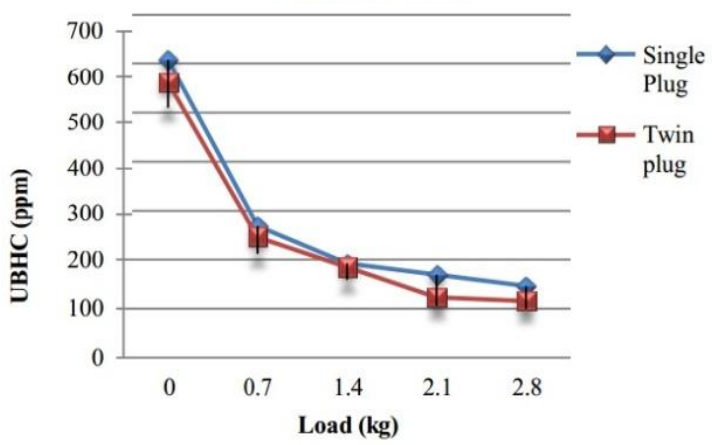

Fig.7. UBHC v/s Load

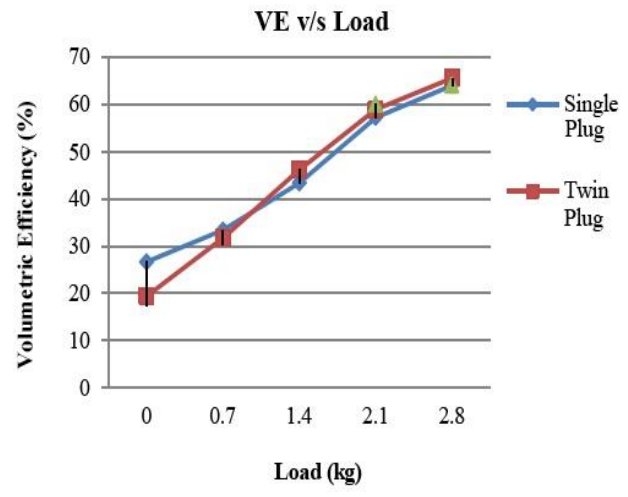

Fig.6. VE v/s Load NOx Emission v/s Load

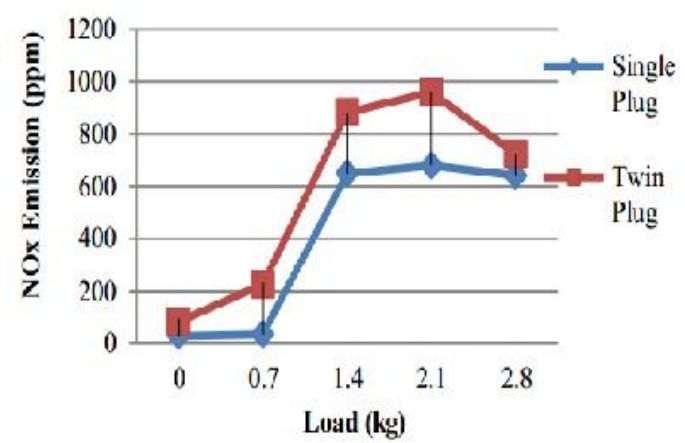

Fig .8.NOx emission v/s Load

The above figure shows the relation between performance of single spark plug and dual spark plug petrol engine. From Fig. 3 it is concluding that the brake thermal efficiency is maximum for dual spark plug mode as well as variation increases with engine load. Fig.4. gives the relation between brake specific fuel consumption and load and from it is conclude that the BSFC is very high at initial stage for both the conditions but maximum for single spark plug engine and minimum for dual spark plug engine.

Fig.5 is the characteristics draw against volumetric efficiency v/s load and from it is concluding that volumetric efficiency of single spark plug is very high at the part load as compared to dual spark plug engine but increase in load increases the volumetric efficiency of dual spark plug whereas Fig.6 show that the emission of $\mathrm{CO}$ is decreases with increasing spark plugs. Fig.7 gives that the UBHC are more with single spark plug where as it is less in dual spark plug mode whereas NOx emission increases with increase in spark plug with respective speed.

\section{CONCLUSION}

Following conclusions are made according to experimental results:

1) Combustion process in dual spark engine takes place $35 \%$ faster than single spark engine due to faster flame propagation.

2) Brake thermal efficiency of twin spark engine is $4.9 \%$ higher than single spark engine.

1) Volumetric efficiency of dual spark engine is $1.2 \%$ less for twin spark engine as compared to single spark engine.

2) The UBHC emission in twin spark engine is reduced up to $12 \%$ as compared to the single spark engine.

3) The $\mathrm{CO}$ emission in twin sparks engine is reduced to a great extent.

4) NOx emission increased by $12 \%$ in twin spark engine as compared to single spark engine at full load.

It is observed experimentally that dual spark engine is clearly a winner amongst both engine types, which gives maximum performance in terms of efficiency and exhaust emissions. So it is suggested that dual spark technology should be preferred in comparison with single spark technology. 


\section{REFERENCES}

[1] Narasimha bailkeri, Krishna Prasad and Shrinivasa Rao B.R, (2013) Comparitive study of Performance of Dual plug and single plug S.I engine at different compression ratios, International Journals Of Advanced Research In Engineering And Technology (IJARET), 4(5). 188-197.

[2] Ajay K.Singh , A.Rehman,( 2013) The Effect of Dual Spark Plug on Engine Performance Parameter in Two Stroke Gasoline Engine, International Journal of Applied Research and Studies (iJARS) ISSN: 2278-9480 Volume 2, Issue 7

[3] Vi H. Rapp, Anthony DeFilippo,Samveg Saxena,Jyh-Yuan Chen,RobertW. Dibble,Atsushi Nishiyama, AhsaMoon, and Yuji Ikeda,(2012) Extending Lean Operating Limit and Reducing Emissions of Methane Spark-Ignited Engines Using a MicrowaveAssisted Spark Plug, Hindawi Publishing Corporation, Journal of Combustion, Volume 2012, Article ID 927081, doi:10.1155/2012/927081.

[4] Atilla BILLGIN, Ismail ALTIN and Ismet SEZER Karadeniz "Investigation of the Effect of Dual Ignition on the Exhaust Emissions of an SI Engine Operating on Different Conditions by Using Quasi-dimensional Thermodynamic Cycle Model," Technical University 61080 Trabzon, Turkey CODEN STJSAO, ZX470/1404 ISSN 0562-1887 UDK 621.434.05:621.434.041.4. 8/2009

[5] S.N. Sridhara, Abdul Nassar and N.L.N. Murthy, S.R. Shankapal Dept of Automotive Engineering M.S. Ramaiah School of Advanced Studies, Bangalore, India " Numerical Investigation of Effect of using Twin Spark Plug on Power and Emission Characteristics in an IC Engine".

[6] Lauvergne R and Hallot J, (2003), "Investigation of the effect of double ignition on the combustion processes in a 2-valves Gasoline engine through 3D simulation", SAE paper no-2003-01-0010.

[7] Bozza F, Gimelli A, Torella E and Mastrangelo G, (2004), "A quasi-dimensional three zone model for performance and combustion noise evaluation of a twin spark high EGR engine”, SAE paper no. 2004-01-0169

[8] A Ismail Altın a, Atilla Bilgin b, "parametric study on the performance parameters of a twin-spark SI engine" Energy Conversion and Management 50 (2009) 1902-1907 Contents lists available at Science Direct Energy Conversion and Management journal homepage: 